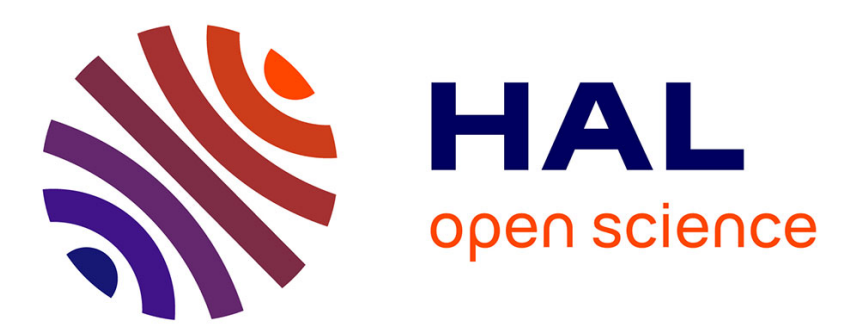

\title{
Second-Order Sliding Mode Control of a Doubly Fed Induction Generator Driven Wind Turbine
}

Brice Beltran, Mohamed Benbouzid, Tarek Ahmed-Ali

\section{To cite this version:}

Brice Beltran, Mohamed Benbouzid, Tarek Ahmed-Ali. Second-Order Sliding Mode Control of a Doubly Fed Induction Generator Driven Wind Turbine. IEEE Transactions on Energy Conversion, 2012, 27 (2), pp.261-269. 10.1109/TEC.2011.2181515 . hal-00705995

\section{HAL Id: hal-00705995 \\ https://hal.science/hal-00705995}

Submitted on 8 Jun 2012

HAL is a multi-disciplinary open access archive for the deposit and dissemination of scientific research documents, whether they are published or not. The documents may come from teaching and research institutions in France or abroad, or from public or private research centers.
L'archive ouverte pluridisciplinaire HAL, est destinée au dépôt et à la diffusion de documents scientifiques de niveau recherche, publiés ou non, émanant des établissements d'enseignement et de recherche français ou étrangers, des laboratoires publics ou privés. 


\title{
Second-Order Sliding Mode Control of a Doubly Fed Induction Generator Driven Wind Turbine
}

\author{
Brice Beltran, Mohamed El Hachemi Benbouzid, Senior Member, IEEE, and Tarek Ahmed-Ali
}

\begin{abstract}
This paper deals with power extraction maximization of a doubly fed induction generator (DFIG)-based wind turbine. These variable speed systems have several advantages over the traditional wind turbine operating methods, such as the reduction of the mechanical stress and an increase in the energy capture. To fully exploit this latest advantage, many control schemes have been developed for maximum power point tracking (MPPT) control schemes. In this context, this paper proposes a second-order sliding mode to control the wind turbine DFIG according to references given by an MPPT. Traditionally, the desired DFIG torque is tracked using control currents. However, the estimations used to define current references drive some inaccuracies mainly leading to nonoptimal power extraction. Therefore, using robust control, such as the second-order sliding mode, will allow one to directly track the DFIG torque leading to maximum power extraction. Moreover, the proposed control strategy presents attractive features such as chattering-free behavior (no extra mechanical stress), finite reaching time, and robustness with respect to external disturbances (grid) and unmodeled dynamics (generator and turbine). Simulations using the wind turbine simulator FAST and experiments on a 7.5-kW real-time simulator are carried out for the validation of the proposed high-order sliding mode control approach.
\end{abstract}

Index Terms-Control, doubly fed induction generator (DFIG), second-order sliding mode (SOSM), wind turbine (WT).

\begin{tabular}{ll} 
WT & \multicolumn{1}{c}{ NOMENCLATURE } \\
DFIG & Doubly fed induction generator. \\
SOSM & Second-order sliding mode. \\
MPPT & Maximum power point tracking. \\
$v$ & Wind speed $(\mathrm{m} / \mathrm{s})$. \\
$\rho$ & Air density $\left(\mathrm{kg} / \mathrm{m}^{3}\right)$. \\
$R$ & Rotor radius $(\mathrm{m})$. \\
$P_{a}$ & Aerodynamic power $(\mathrm{W})$. \\
$T_{a}$ & Aerodynamic torque $(\mathrm{N} \cdot \mathrm{m})$. \\
$\lambda$ & Tip speed ratio. \\
$C_{p}(\lambda)$ & Power coefficient. \\
$\omega_{m r}$ & WT rotor speed $(\mathrm{rad} / \mathrm{s})$. \\
$\omega_{m g}$ & Generator speed $(\mathrm{rad} / \mathrm{s})$.
\end{tabular}

Manuscript received May 26, 2011; revised September 23, 2011 and November 18, 2011; accepted December 16, 2011. Date of publication January 13, 2012; date of current version May 18, 2012. Paper no. TEC-00255-2011.

B. Beltran and M. E. H. Benbouzid are with the University of Brest, EA 4325 LBMs, 29238 Brest Cedex 03, France (e-mail: brice.beltran@ dga.defense.gouv.fr; Mohamed.Benbouzid@univ-brest.fr).

T. Ahmed-Ali is with the University of Caen, UMR CNRS 6072 GREYC, Campus Côte de Nacre, 14032 Caen, Cedex, France (e-mail: Tarek.AhmedAli@greyc.ensicaen.fr).

Color versions of one or more of the figures in this paper are available online at http://ieeexplore.ieee.org.

Digital Object Identifier 10.1109/TEC.2011.2181515

$\begin{array}{ll}T_{g} & \text { Generator electromagnetic torque }(\mathrm{N} \cdot \mathrm{m}) . \\ J_{t} & \text { Turbine total inertia }\left(\mathrm{kg} \cdot \mathrm{m}^{2}\right) . \\ K_{t} & \text { Turbine total external damping }(\mathrm{N} \cdot \mathrm{m} / \mathrm{rad} \cdot \mathrm{s}) . \\ d, q & \text { Synchronous reference frame index. } \\ s,(r) & \text { Stator (rotor) index. } \\ V(I) & \text { Voltage (current). } \\ P(Q) & \text { Active (reactive) power. } \\ \phi & \text { Flux. } \\ T_{e m} & \text { Electromagnetic torque. } \\ R & \text { Resistance. } \\ L(M) & \text { Inductance (mutual inductance). } \\ \sigma & \text { Leakage coefficient, } \sigma=1-M^{2} / L_{s} L_{r} \cdot \\ \theta_{r} & \text { Rotor position. } \\ \omega_{r}\left(\omega_{s}\right) & \text { Angular speed (Synchronous speed). } \\ s & \text { Slip. } \\ p & \text { Pole pair number. }\end{array}$

\section{INTRODUCTION}

A CTUALLY, variable speed WTs are continuously increasing their market share, since it is possible to track the changes in wind speed by adapting shaft speed and, thus, maintaining optimal power generation. The more the variable speed WTs are investigated, the more it becomes obvious that their behavior is significantly affected by the control strategy used. Typically, they use aerodynamic controls in combination with power electronics to regulate torque, speed, and power. The aerodynamic control systems, usually variable-pitch blades or trailing-edge devices, are expensive and complex, especially when the turbines are larger [1]. This situation provides a motivation to consider alternative control approaches [2].

The main control objective of variable speed WTs is power extraction maximization. To reach this goal, the turbine tip speed ratio should be maintained at its optimum value despite wind variations. Nevertheless, control is not always aimed at capturing as much energy as possible. In fact, in previously rated wind speed, the captured power needs to be limited. Although there are both mechanical and electrical constraints, the more severe ones are commonly on the generator and the converter. Hence, regulation of the power produced by the generator is usually intended and this is the main objective of this paper for a DFIG-based WT using an SOSM [3]. Experiments on a 7.5-kW real-time simulator are carried out for the validation of the proposed high-order sliding mode control approach.

\section{WT Modeling [4]}

The global scheme for a grid-connected WT is given in Fig. 1 . 


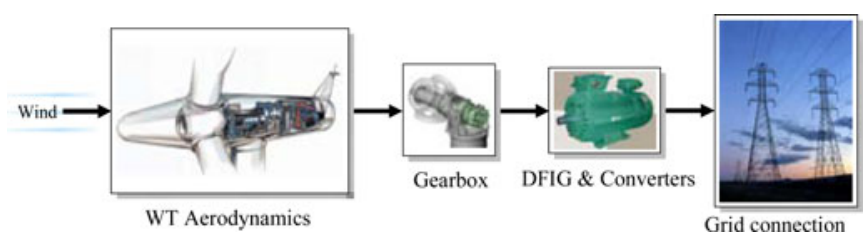

Fig. 1. WT global scheme.

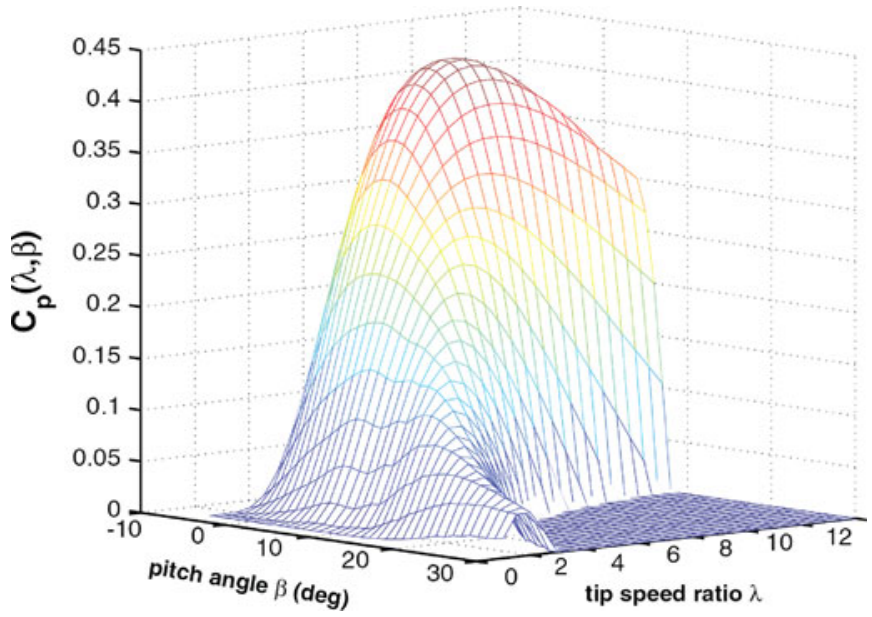

Fig. 2. WT power coefficient.

\section{A. Turbine Model}

The turbine modeling is inspired from [4]. In this case, the aerodynamic power $P_{a}$ captured by the WT is given by

$$
P_{a}=\frac{1}{2} \pi \rho R^{2} C_{p}(\lambda) v^{3}
$$

where

$$
\lambda=\frac{R \omega_{m r}}{v} .
$$

The $C_{p}-\lambda$ characteristics, for different values of the pitch angle $\beta$, are illustrated in Fig. 2. This figure indicates that there is one specific $\lambda$ at which the turbine is most efficient. Normally, a variable speed WT follows the $C_{p \max }$ to capture the maximum power up to the rated speed by varying the rotor speed to keep the system at $\lambda_{\text {opt }}$. Then, it operates at the rated power with power regulation during high wind periods by active control of the blade pitch angle or passive regulation based on aerodynamic stall.

The rotor power (aerodynamic power) is also defined by

$$
P_{a}=\omega_{m r} T_{a} .
$$

According to [4], the following simplified model is adopted for the turbine (drive train) for control purposes:

$$
J_{t} \dot{\omega}_{m r}=T_{a}-K_{t} \omega_{m r}-T_{g} .
$$

\section{B. Generator Model}

The WT adopted generator is the DFIG (see Fig. 3). DFIGbased WT will offer several advantages including variable speed

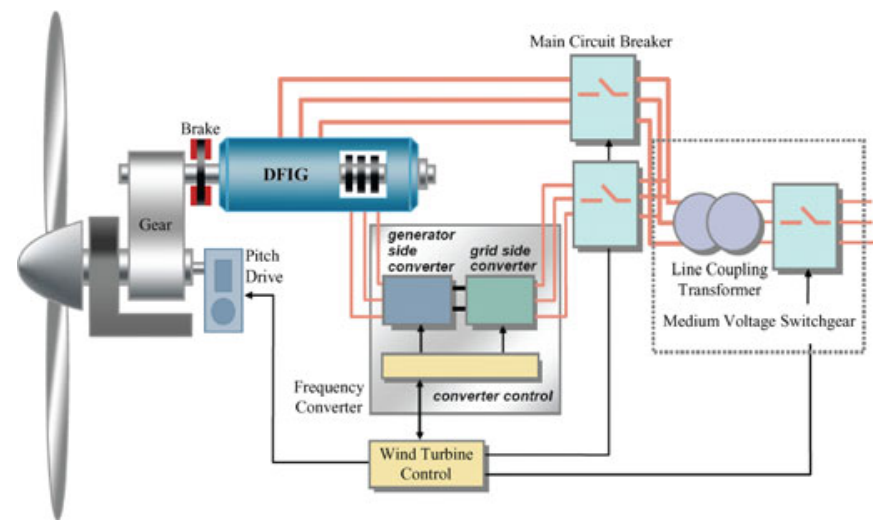

Fig. 3. Schematic diagram of a DFIG-based WT.

operation ( $\pm 33 \%$ around the synchronous speed), and fourquadrant active and reactive power capabilities. Such system also results in lower converter costs (typically $25 \%$ of total system power) and lower power losses compared to a system based on a fully fed synchronous generator with full-rated converter.

Moreover, the generator is robust and requires little maintenance [5].

The control system is usually defined in the synchronous $d q$ frame fixed to either the stator voltage or the stator flux. For the proposed control strategy, the generator dynamic model written in a synchronously rotating frame $d q$ is given by

$$
\left\{\begin{array}{c}
V_{s d}=R_{s} I_{s d}+\frac{d \phi_{s d}}{d t}-\omega_{s} \phi_{s q} \\
V_{s q}=R_{s} I_{s q}+\frac{d \phi_{s q}}{d t}+\omega_{s} \phi_{s d} \\
V_{r d}=R_{r} I_{r d}+\frac{d \phi_{r d}}{d t}-\omega_{r} \phi_{r q} \\
V_{r q}=R_{r} I_{r q}+\frac{d \phi_{r q}}{d t}+\omega_{r} \phi_{r d} \\
\phi_{s d}=L_{s} I_{s d}+M I_{r d} \\
\phi_{s q}=L_{s} I_{s q}+M I_{r q} \\
\phi_{r d}=L_{r} I_{r d}+M I_{s d} \\
\phi_{r q}=L_{r} I_{r q}+M I_{s q} \\
T_{\mathrm{em}}=p M\left(I_{r d} I_{s q}-I_{r q} I_{s d}\right) .
\end{array}\right.
$$

For simplification purposes, the $q$-axis is aligned with the stator voltage and the stator resistance is neglected [6]. These will lead to

$$
\left\{\begin{array}{l}
\frac{d I_{r d}}{d t}=\frac{1}{\sigma L_{r}}\left(V_{r d}-R_{r} I_{r d}+s \omega_{s} \sigma L_{r} I_{r q}-\frac{M}{L_{s}} \frac{d \phi_{s d}}{d t}\right) \\
\frac{d I_{r q}}{d t}=\frac{1}{\sigma L_{r}}\left(V_{r q}-R_{r} I_{r q}-s \omega_{s} \sigma L_{r} I_{r d}-s \omega_{s} \frac{M}{L_{s}} \phi_{s d}\right) \\
T_{\mathrm{em}}=-p \frac{M}{L_{s}} \phi_{s d} I_{r q} .
\end{array}\right.
$$

\section{CONTROL OF THE DFIG-BASED WT}

\section{A. Problem Formulation}

WTs are designed to produce electrical energy as cheaply as possible. Therefore, they are generally designed so that they yield maximum output at wind speeds around $15 \mathrm{~m} / \mathrm{s}$. In case 


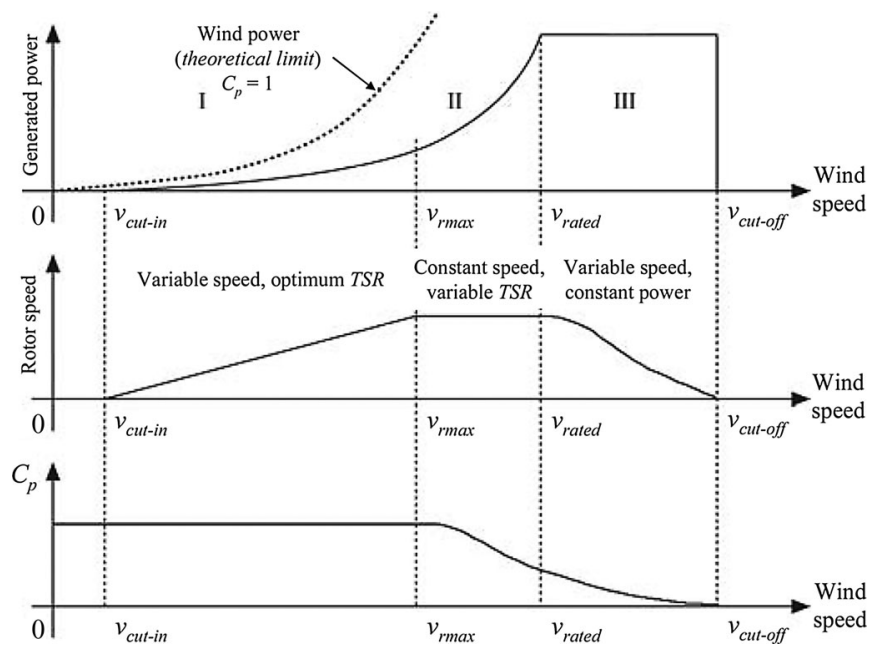

Fig. 4. WT control regions.

of stronger winds, it is necessary to waste part of the excess energy of the wind in order to avoid damaging the WT. All WTs are, therefore, designed with some sort of power control. This standard control law keeps the turbine operating at the peak of its $C_{p}$ curve

$$
T_{\text {ref }}=k \omega^{2}, \text { with } k=\frac{1}{2} \pi \rho R^{5} \frac{C_{p \max }}{\lambda_{\text {opt }}^{3}} .
$$

There is a significant problem with this standard control. Indeed, wind speed fluctuations force the turbine to operate off the peak of its $C_{p}$ curve much of the time. Tight tracking $C_{p \max }$ would lead to high mechanical stress and transfer aerodynamic fluctuations in to the power system. This, however, will result in less energy capture.

To effectively extract wind power while at the same time maintaining safe operation, the WT should be driven according to the following three fundamental operating regions associated with wind speed, maximum allowable rotor speed, and rated power. The three distinct regions are shown in Fig. 4, where $v_{r \max }$ is the wind speed at which the maximum allowable rotor speed is reached, while $v_{\text {cutoff }}$ is the furling wind speed at which the turbine needs to be shut down for protection. In practice, there are three possible regions of turbine operation, namely the high-, constant-, and low-speed regions. High-speed operation (III) is frequently bounded by the power limit of the machine while speed constraints apply in the constant-speed region. Conversely, regulation in the low-speed region (I) is usually not restricted by speed constraints. However, the system has nonlinear nonminimum phase dynamics in this region. This adverse behavior is an obstacle to perform the regulation task [7].

A common practice in addressing DFIG control problem is to use a linearization approach [8]-[10]. However, due to the stochastic operating conditions and the inevitable uncertainties inherent in DFIG-based WTs, much of these control methods come at the price of poor system performance and low reliability. Hence, the need for nonlinear and robust control to take into account these control problems. Although many modern tech- niques can be used for this purpose [11], sliding mode control has proved to be especially appropriate for nonlinear systems, presenting robust features with respect to system parameter uncertainties and external disturbances. For WT control, sliding mode should provide a suitable compromise between conversion efficiency and torque oscillation smoothing [4], [12], [13].

Sliding mode control copes with system uncertainty keeping a properly chosen constraint by means of high-frequency control switching. Featuring robustness and high accuracy, the standard (first-order) sliding mode usage is, however, restricted due to the chattering effect caused by the control switching, and the equality of the constraint relative degree to 1 .

High-order sliding mode approach suggests treating the chattering effect using a time derivative of control as a new control, thus integrating the switching [14]-[16].

\section{B. SOSMs Control Design}

As the chattering phenomenon is the major drawback of practical implementation of sliding mode control, the most efficient ways to cope with this problem is higher order sliding mode. This technique generalizes the basic sliding mode idea by acting on the higher order time derivatives of the sliding manifold, instead of influencing the first time derivative as it is the case in the standard (first order) sliding mode. This operational feature allows mitigating the chattering effect, keeping the main properties of the original approach [17].

The DFIG stator-side reactive power is given by

$$
Q_{s}=\frac{3}{2}\left(V_{s q} I_{s d}-V_{s d} I_{s q}\right) .
$$

For a decoupled control, a $d q$ reference frame attached to the stator flux was used. Therefore, setting the stator flux vector aligned with the $d$-axis, the reactive power can be expressed as

$$
Q_{s}=\frac{3}{2} \frac{V_{s}}{L_{s}}\left(\phi_{s}-M I_{r d}\right) .
$$

Setting the reactive power to zero will, therefore, lead to the rotor reference current

$$
I_{r d_{\text {_ref }}}=\frac{V_{s}}{\omega_{s} M} .
$$

The DFIG-based WT control objective is to optimize the wind energy capture by tracking the optimal torque $T_{\text {ref }}$ (7). This control objective can be formulated by the following tracking errors:

$$
\left\{\begin{array}{l}
e_{I_{r d}}=I_{r d}-I_{r d \_r e f} \\
e_{T_{\mathrm{em}}}=T_{\mathrm{em}}-T_{\text {ref }} .
\end{array}\right.
$$

Then, we will have

$$
\left\{\begin{aligned}
\dot{e}_{I_{r d}} & =\frac{1}{\sigma L_{r}} \\
& \times\left(V_{r d}-R_{r} I_{r d}+s \omega_{s} L_{r} \sigma I_{r q}-\frac{M}{L_{s}} \frac{d \phi_{s d}}{d t}\right)-\dot{I}_{r d \_ \text {ref }} \\
\dot{e}_{T_{\mathrm{em}}} & =-p \frac{M}{\sigma L_{s} L_{r}} \phi_{s} \\
& \times\left(V_{r q}-R_{r} I_{r q}-s \omega_{s} L_{r} \sigma I_{r d}-s \omega_{s} \frac{M}{L_{s}} \phi_{s d}\right)-\dot{T}_{\mathrm{ref}} .
\end{aligned}\right.
$$


If we define the functions $G_{1}$ and $G_{2}$ as follows:

$$
\left\{\begin{aligned}
G_{1}= & \frac{1}{\sigma L_{r}}\left(s \omega_{s} \sigma L_{r} I_{r q}-\frac{M}{L_{s}} \frac{d \phi_{s d}}{d t}-R_{r} I_{r d}\right)-\dot{I}_{r d \_r e f} \\
G_{2}= & -p \frac{M}{\sigma L_{s} L_{r}} \phi_{s} \\
& \times\left(-R_{r} I_{r q}-s \omega_{s} \sigma L_{r} I_{r d}-s \omega_{s} \frac{M}{L_{s}} \phi_{s d}\right)-\dot{T}_{\text {ref }}
\end{aligned}\right.
$$

then we have

$$
\left\{\begin{array}{l}
\ddot{e}_{I_{r d}}=\frac{1}{\sigma L_{r}} \dot{V}_{r d}+\dot{G}_{1} \\
\ddot{e}_{\Gamma_{\mathrm{em}}}=-p \frac{M}{\sigma L_{s} L_{r}} \phi_{s} \dot{V}_{r q}+\dot{G}_{2} .
\end{array}\right.
$$

To overcome standard sliding mode control chattering, a natural modification is to replace the discontinuous function in the vicinity of the discontinuity by a smooth approximation. Nevertheless, such a smooth approximation is not easy to carry out. This is why common approaches use current references. Therefore, a high-order sliding mode seems to be a good alternative.

The main problem with high-order sliding mode algorithm implementations is the increased required information. Indeed, the implementation of an $n$ th-order controller requires the knowledge of $\dot{S}, \ddot{S}, \ldots, S^{(n-1)}$. The exception is the supertwisting algorithm, which only needs information about the sliding surface $S$ [17]. Therefore, the proposed control approach has been designed using this algorithm.

Now, let us consider the following SOSM controller based on the supertwisting algorithm [17]. In the considered case, the control could be approached by two independent SOSM controllers. Indeed, the control matrix is approximated by a diagonal one. Hence, $V_{r d}$ controls $I_{r d}$ (reactive power) and $\mathrm{V}_{r q}$ controls the torque MPPT strategy

$$
\begin{cases}V_{r d}=y_{1}-B_{1}\left|e_{I_{r d}}\right|^{1 / 2} \operatorname{sgn}\left(e_{I_{r d}}\right), & \dot{y}_{1}=-B_{2} \operatorname{sgn}\left(e_{I_{r d}}\right) \\ V_{r q}=y_{2}+B_{3}\left|e_{T_{\mathrm{em}}}\right|^{1 / 2} \operatorname{sgn}\left(e_{T_{\mathrm{em}}}\right), & \dot{y}_{2}=+B_{4} \operatorname{sgn}\left(e_{T_{\mathrm{em}}}\right)\end{cases}
$$

where the constants $B_{1}, B_{2}, B_{3}$, and $B_{4}$ are defined as

$$
\left\{\begin{array}{l}
B_{1}^{2}>\frac{2 \sigma^{2} L_{r}^{2}\left(\left(B_{2} / \sigma L_{r}\right)+\Phi_{1}\right)}{\left(\left(B_{2} / \sigma L_{r}\right)-\Phi_{1}\right)}, \quad B_{2}>\sigma L_{r} \Phi_{1}, \quad\left|\dot{G}_{1}\right|<\Phi_{1} \\
B_{3}^{2}>2\left(\frac{\sigma L_{s} L_{r}}{p M}\right)^{2} \frac{\left(p\left(M / \sigma L_{s} L_{r}\right) B_{4}+\Phi_{2}\right)}{\left(p\left(M / \sigma L_{s} L_{r}\right) B_{4}-\Phi_{2}\right)}, \quad B_{4}>\frac{\sigma L_{s} L_{r}}{p M} \Phi_{2} \\
\left|\dot{G}_{2}\right|<\Phi_{2} .
\end{array}\right.
$$

Proof: Let us consider the case of $V_{r d}$. In this case, we have

$$
\ddot{e}_{I_{r d}}=\frac{1}{\sigma L_{r}}\left(-B_{2} \operatorname{sgn}\left(e_{I_{r d}}\right)-B_{1} \frac{1}{2} \frac{\dot{e}_{I_{r d}}}{\left|e_{I_{r d}}\right|^{1 / 2}}\right)+\dot{G}_{1}
$$

and, therefore, the supertwisting algorithm phase trajectory is illustrated in Fig. 5.

Assume now, for simplicity, that the initial values are $e_{I_{r d}}=0$ and $\dot{e}_{I_{r d}}=\dot{e}_{0}>0$ at $t=0$. Let $e_{M}$ be the intersection of the curve $\ddot{e}_{I_{r d}}=-\left(B_{2} / \sigma L_{r}-\Phi_{1}\right)$ with $\dot{e}_{I_{r d}}=0$. We have then

$$
2 e_{M}\left(\frac{B_{2}}{\sigma L_{r}}-\Phi_{1}\right)=\dot{e}_{0}^{2}
$$

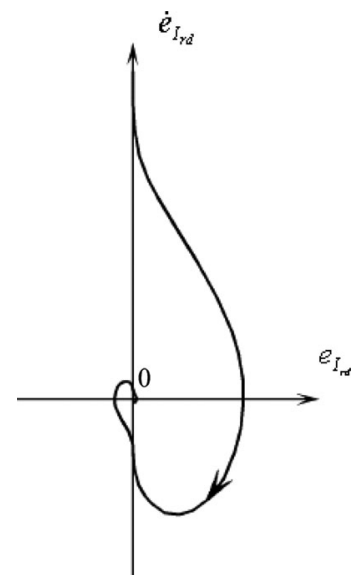

Fig. 5. Supertwisting algorithm phase trajectory.

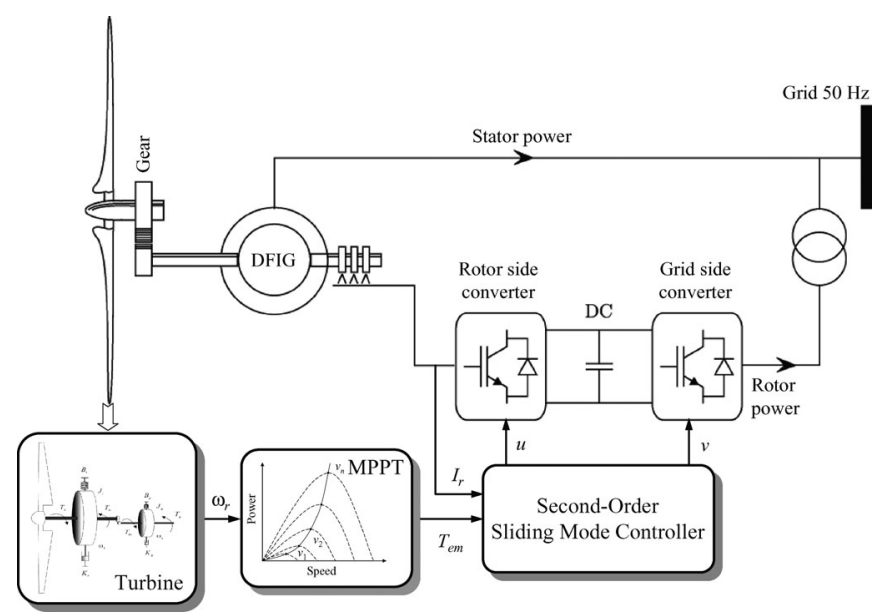

Fig. 6. Proposed control structure.

$$
e_{I_{r d}}>0, \dot{e}_{I_{r d}}<-\frac{2}{B_{1}}\left(\sigma L_{r} \Phi_{1}+B_{2}\right) e_{I_{r d}}^{2} \Rightarrow \ddot{e}_{I_{r d}}>0
$$

Thus, the majorant curve with $e_{I_{r d}}>0$ may be taken as

$$
\left\{\begin{array}{l}
\dot{e}_{I_{r d}}^{2}=2\left(\frac{B_{2}}{\sigma L_{r}}-\Phi_{1}\right)\left(e_{M}-e_{I_{r d}}\right) \quad \text { with } \dot{e}_{I_{r d}}>0 \\
e_{I_{r d}}=e_{M} \text { with } 0 \geq \dot{e}_{I_{r d}} \geq-\frac{2}{B_{1}}\left(\sigma L_{r} \Phi_{1}+B_{2}\right) e_{I_{r d}}^{1 / 2} \\
\dot{e}_{I_{r d}}=\dot{e}_{M}=-\frac{2}{B_{1}}\left(\sigma L_{r} \Phi_{1}+B_{2}\right) e_{M}^{1 / 2} \\
\text { with } \dot{e}_{I_{r d}}>-\frac{2}{B_{1}}\left(\sigma L_{r} \Phi_{1}+B_{2}\right) e_{I_{r d}}^{1 / 2} .
\end{array}\right.
$$

Let the trajectory next intersection with $e_{I_{r d}}=0$ axis be $e_{1}$. Then, it follows that

$\left|\frac{\dot{e}_{1}}{\dot{e}_{0}}\right| \leq q$ with $q=\left|\frac{\dot{e}_{M}}{\dot{e}_{0}}\right|=\sqrt{\frac{2\left(\left(B_{2} / \sigma L_{r}\right)+\Phi_{1}\right)}{\left(B_{1} / \sigma L_{r}\right)^{2}\left(\left(B_{2} / \sigma L_{r}\right)-\Phi_{1}\right)}}$.

Extending the trajectory into the half plane $e_{I_{\text {rd }}}<0$ and carrying out a similar reasoning show that successive crossings of the $e_{I_{r d}}=0$ axis satisfy the inequality

$$
\left|\frac{\dot{e}_{i+1}}{\dot{e}_{i}}\right| \leq q
$$




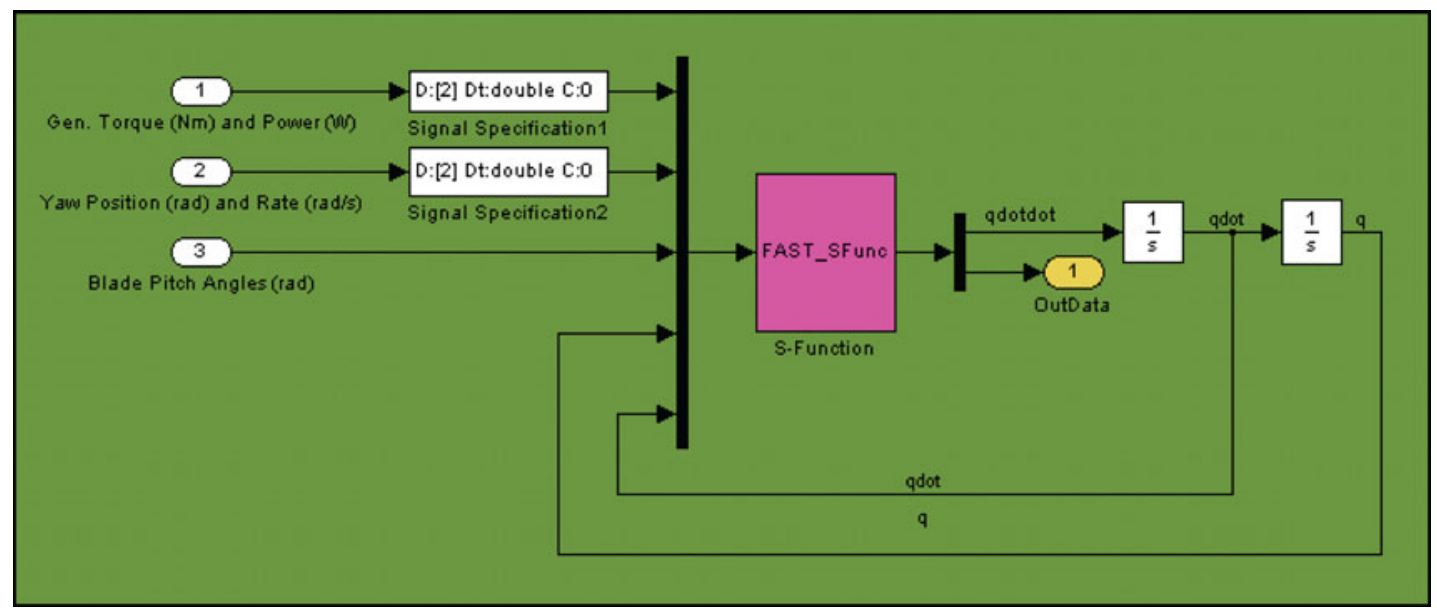

Fig. 7. FAST WT block.

The $q<1$ condition is sufficient for the algorithm convergence. Indeed, the real trajectory consists of an infinite number of segments. The function total variance is given by

$$
\operatorname{Var}\left(\dot{e}_{I_{r d}}\right)=\sum\left|\dot{e}_{i}\right| \leq\left|\dot{e}_{0}\right|\left(1+q+q^{2}+\cdots\right)=\frac{\left|\dot{e}_{0}\right|}{1-q} .
$$

Therefore, the algorithm converges.

The convergence time is to be estimated now. Consider an auxiliary variable

$$
\eta=\frac{1}{\sigma L_{r}} y_{1}+G_{1}
$$

$\eta=\dot{e}_{I_{r d}}$ when $e_{I_{r d}}=0$, and $y_{1} \rightarrow \sigma L_{r} G_{1}$ as $t \rightarrow \infty$. Thus, $\eta$ tends to zero. Its derivative

$$
\dot{\eta}=-\frac{1}{\sigma L_{r}} B_{2} \operatorname{sgn}\left(e_{I_{r d}}\right)+\dot{G}_{1}
$$

satisfies the inequalities

$$
0<\frac{B_{2}}{\sigma L_{r}}-\Phi_{1} \leq-\dot{\eta} \operatorname{sgn}\left(e_{I_{r d}}\right) \leq \frac{B_{2}}{\sigma L_{r}}+\Phi_{1} .
$$

The real trajectory consists of an infinite number of segments between $\eta_{i}=\dot{e}_{i}$ and $\eta_{i+1}=\dot{e}_{i+1}$ associated with the time $t_{i}$ and $t_{i+1}$, respectively. Consider $t_{I_{r d}}$, the total convergence time

$$
\left\{\begin{array}{l}
t_{I_{r d}}=\sum\left(t_{i+1}-t_{i}\right) \leq \sum \frac{\left|\eta_{i}\right|}{\left(\left(B_{2} / \sigma L_{r}\right)-\Phi_{1}\right)} \\
t_{I_{r d}} \leq \frac{1}{\left(\left(B_{2} / \sigma L_{r}\right)-\Phi_{1}\right)} \sum\left|\dot{e}_{i}\right| \\
t_{I_{r d}} \leq \frac{\left|\dot{e}_{0}\right|}{\left(\left(B_{2} / \sigma L_{r}\right)-\Phi_{1}\right)(1-q)} .
\end{array}\right.
$$

Thus, there exists finite times $t_{T e m}$ and $t_{I r d}$ so as

$$
\begin{cases}I_{r d_{\_} \text {ref }}=I_{r d} & \forall t>t_{I_{r d}} \\ T_{\text {ref }}=T_{\mathrm{em}} & \forall t>t_{T_{\mathrm{em}}}\end{cases}
$$

This means that the control objective is achieved.

In practice, the parameters are never assigned according to inequalities. Usually, the real system is not exactly known, the model itself is not really adequate, and the parameters estimations are much larger than the actual values. The larger the controller parameters, the more sensitive the controller to any switching measurement noises. The right way is to adjust the controller parameters during computer simulations.

The earlier proposed SOSM control strategy for a DFIGbased WT is illustrated by the block diagram in Fig. 6 .

\section{Simulation Results Using FAST WT Simulator}

The proposed SOSM control strategy has been tested for validation using the NREL FAST code [4], [18], [19]. The fatigue, aerodynamics, structures, and turbulence (FAST) code is a comprehensive aeroelastic simulator capable of predicting both the extreme and fatigue loads of two- and three-bladed horizontalaxis WTs. This simulator has been chosen for validation because it is proven that the structural model of FAST is of higher fidelity than other codes [20].

An interface has been developed between FAST and MATLAB Simulink enabling users to implement advanced turbine controls in Simulink convenient block diagram form (see Fig. 7).

Hence, an electrical model (DFIG, grid, control system, etc.) designed in the Simulink environment is simulated while making use of the complete nonlinear aerodynamic WT motion equations available in FAST (see Fig. 8). This introduces tremendous flexibility in WT controls implementation during simulation.

\section{A. Test Conditions}

Numerical validations, using FAST with MATLAB Simulink have been carried out on the NREL WP 1.5-MW WT. The WT and the DFIG ratings are given in the Appendix.

\section{B. Simulation Results}

Validation tests were performed using turbulent FAST wind data with 7 and $14 \mathrm{~m} / \mathrm{s}$ minimum and maximum wind speeds, respectively (see Fig. 9).

As clearly shown in Figs. 10 and 11, very good tracking performances are achieved in terms of DFIG rotor current and WT torque with respect to wind fluctuations. The proposed SOMS control strategy does not induce increased mechanical 


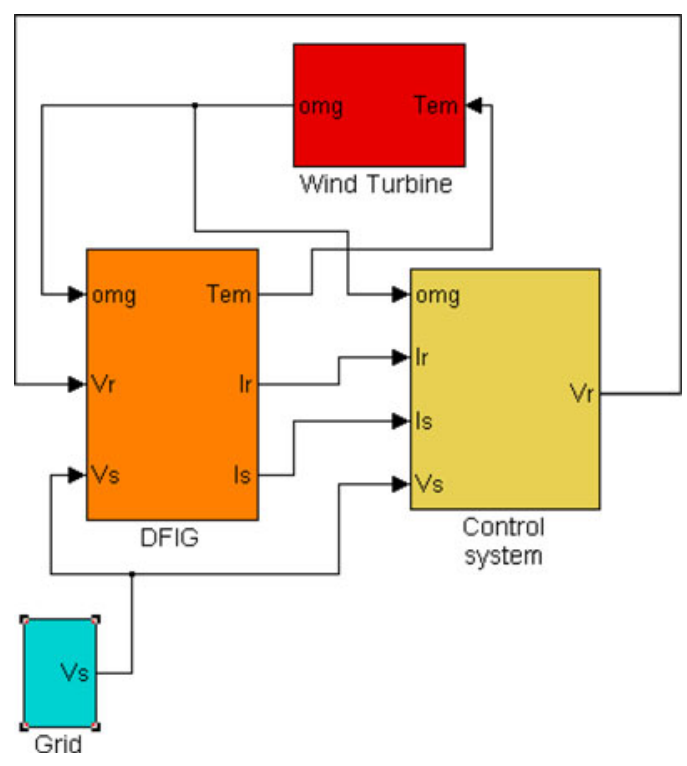

Fig. 8. Simulink model.

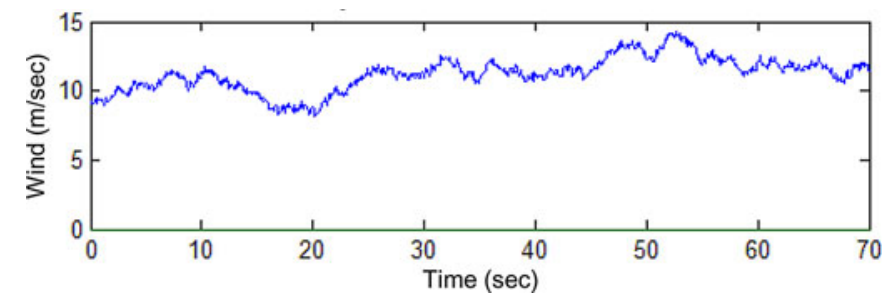

Fig. 9. Wind speed profile.

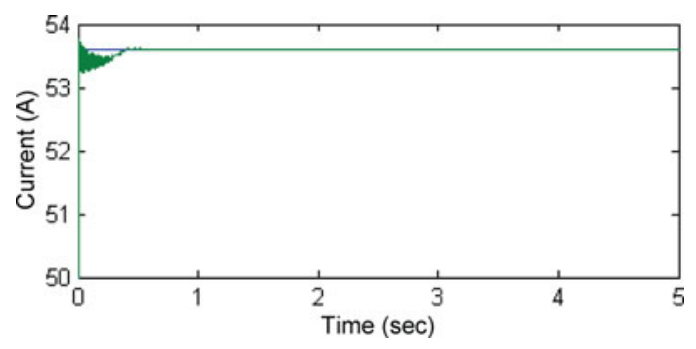

Fig. 10. Current $I_{r d}$ tracking performance: reference (blue) and real (green).

stress as there are no strong torque variations. Indeed and as expected, the aerodynamic torque remains smooth (see Fig. 11).

To assess the effectiveness of the proposed advanced control strategy, it has been compared to more traditional techniques with the same control objectives. The first one is that using the active power as reference [21]

$$
P_{\text {ref }}=T_{\text {ref }} \omega=k \omega^{3} \Rightarrow I_{r q-\text { ref }}=-\frac{L_{s}}{V_{s} M} P_{\text {ref }} .
$$

This approach supposes that the active power is equal to the DFIG electromagnetic power. This approximation drives a dif-

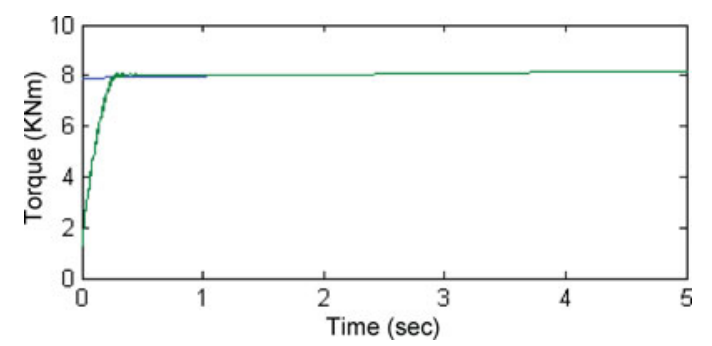

Fig. 11. Torque tracking performance: reference (blue) and real (green).

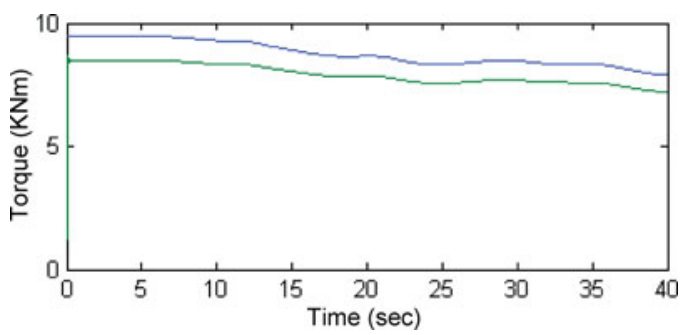

Fig. 12. Torque: reference (blue) and real (green) [21].

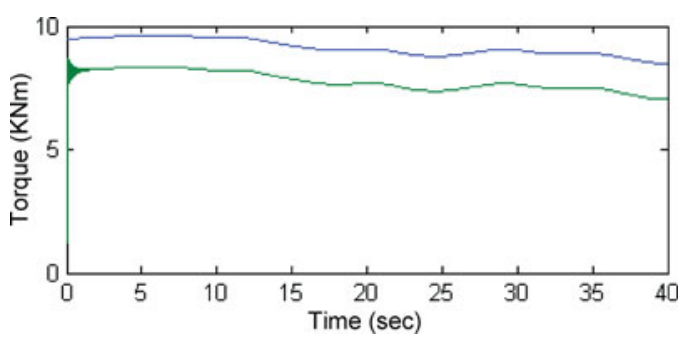

Fig. 13. Torque: reference (blue) and real (green) [22].

ference between the desired torque given by (7) and the generated torque (see Fig. 12).

The second assessed approach is the one using the following reference [22]:

$$
I_{r q \_ \text {ref }}=-\frac{L_{s}}{p M \phi_{s}} T_{\text {ref }} .
$$

In this case, bad tracking performances are also achieved (see Fig. 13). Indeed, the control reference is quite inaccurate due to some adopted simplifications (e.g., a constant stator flux).

In terms of power extraction and maximization, Fig. 14 shows the effectiveness of the proposed SOSM control with respect to (25) approach. This is mainly due to an inaccurate determination of $k_{\text {opt }}$ (7). Indeed, there is no accurate way to determine $k$, especially since blade aerodynamics can change significantly over time. This fact is, therefore, an extra justification of the proposed control strategy. If it is assumed that $k$ can be accurately determined via simulations or experiments, Fig. 15 shows that (24) and (25) approaches bad torque tracking can be balanced by the adjustment of $k_{\mathrm{opt}}$. This delicate task, which requires a number of simulation tests, remains less efficient as it is illustrated in Fig. 16. 


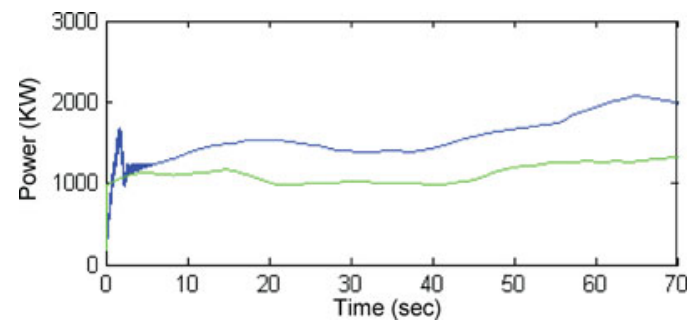

Fig. 14. Generated power: SOSM (blue) and (25) approach (green).

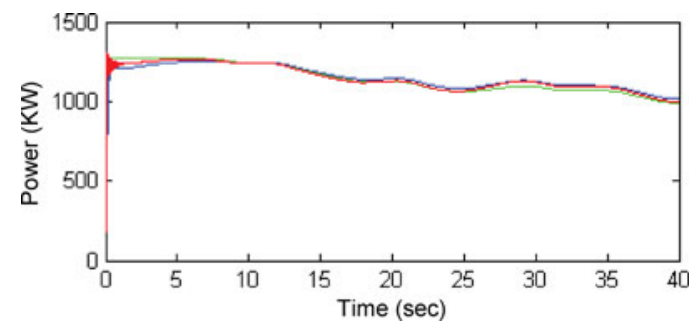

Fig. 15. Generated power: HOSM (blue), (24), and (25) approaches (green and red) with $k_{\text {opt }}$ adjustment.

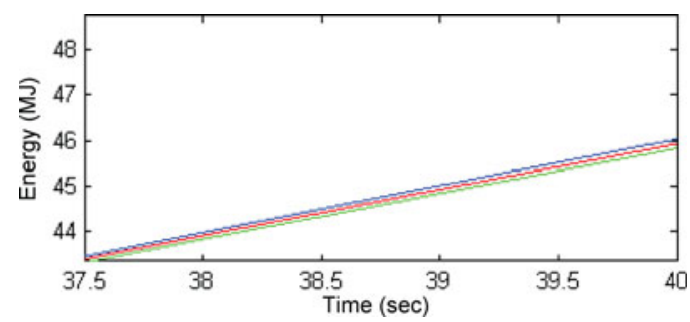

Fig. 16. Generated energy: HOSM (blue), (24), and (25) approaches (green and red) with $k_{\text {opt }}$ adjustment.

\section{EXPERIMENTAL RESULTS}

\section{A. Test Bench}

The test bench presented in Fig. 17 allows the physical simulation of the WT power system. The WT is emulated by a dc motor, which reproduces the torque and the inertia with respect to wind speeds and turbine rotational speed. The dc motor is coupled to a 7.5-kW DFIG (see the Appendix) [14].

\section{B. Experimental Tests}

Figs. 18 and 19 show experimental control performances of the emulated DFIG-based WT. These results show very good tracking performances in terms of the DFIG torque and rotor current. Indeed, Fig. 18 illustrates good tracking of the desired torque given by the MPPT. This is an indication that the WT power capture is optimized.

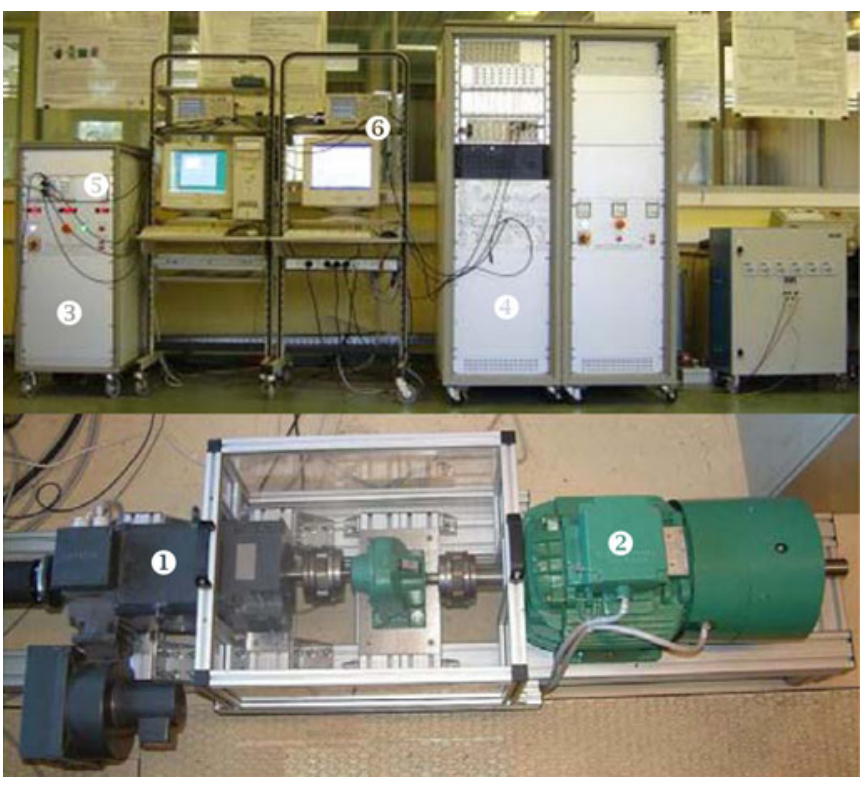

Fig. 17. Components of the G2Elab test bench, Grenoble, France: (1) dc motor, (2) DFIG, (3) Power electronics for driving the dc motor, (4) Power electronics for driving the DFIG, (5) DSP TMS320F240 implementing dc motor control, (6) DSP DS1005 (dSPACE) implementing PMSG-based MCT control.

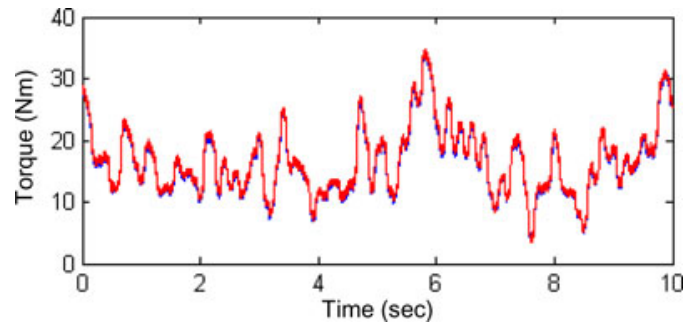

Fig. 18. Torque: reference (red) and real (blue).

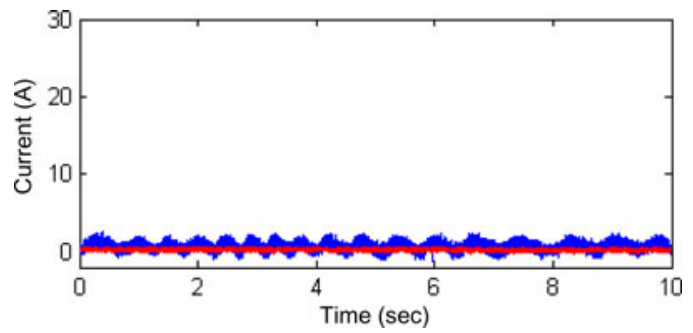

Fig. 19. $I_{r d}$ : reference (red) and real (blue).

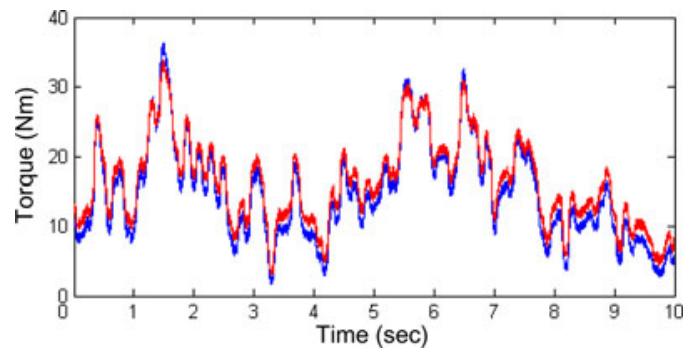

Fig. 20. Torque: reference (red) and real (blue). 


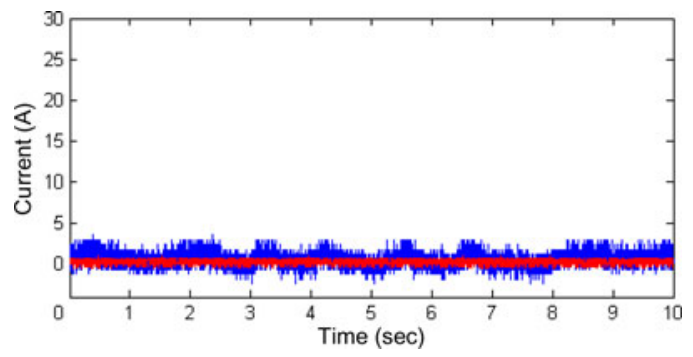

Fig. 21. $\quad I_{r d}$ : reference (red) and real (blue).

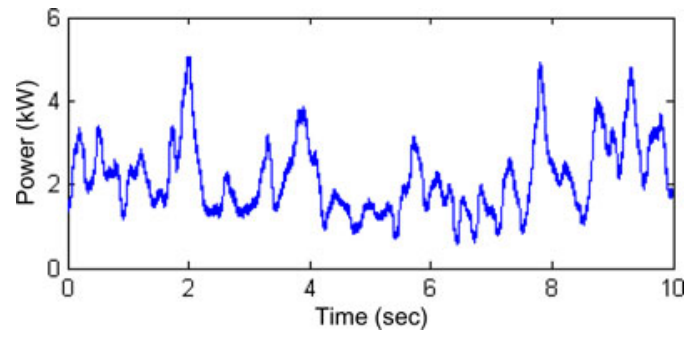

Fig. 22. DFIG generated power.

For comparison purposes, a classical PI control, using current references, has been tested. Figs. 20 and 21 show the achieved performances. In this case, poor torque tracking performances are achieved (see Fig. 20).

In the case of $I_{r d}$ tracking, which allows the reactive power minimization, one can observe chattering with SOSM control (see Fig. 19). This is mainly due to measurements as it is confirmed by PI control (see Fig. 21). It should be mentioned that this phenomenon is largely amplified by Park transform.

For illustration, Fig. 22 shows the generated power.

\section{CONCLUSION}

This paper dealt with an SOSM control of doubly fed induction-based WT. Its main features are a chattering-free behavior, a finite reaching time, and robustness with respect to external disturbances (grid) and unmodeled dynamics (DFIG and WT). The proposed SOSM control the WT DFIG according to references given by an MPPT. In this case, the DFIG torque is directly tracked, therefore leading to maximum power extraction.

The proposed control strategy has been tested using the NREL FAST simulator on a 1.5-MW three-blade DFIG-based WT. Moreover, experiments on a $7.5-\mathrm{kW}$ real-time simulator have been carried out. The obtained results clearly show the SOSM approach effectiveness in terms of power extraction maximization compared to more traditional techniques. Moreover, it has been confirmed that there is no mechanical extra stress induced on the WT drive train as there are no strong torque variations.
APPENDIX

CHARACTERISTICS OF THE SIMULATED WT:

\begin{tabular}{c|c}
\hline \hline Number of blades & 3 \\
\hline Rotor diameter & $70 \mathrm{~m}$ \\
\hline Hub height & $84.3 \mathrm{~m}$ \\
\hline Rated power & $1.5 \mathrm{MW}$ \\
\hline Turbine total inertia & $4.4532 \times 10^{5} \mathrm{~kg} \cdot \mathrm{m}^{2}$ \\
\hline \hline
\end{tabular}

PARAMETERS OF THE SiMULATED DFIG

$R_{s}=0.005 \Omega, L_{s}=0.407 \mathrm{mH}, R_{r}=0.0089 \Omega, L_{r}=0.299 \mathrm{mH}$

$M=0.016 \mathrm{mH}, p=2$

\begin{tabular}{c} 
CONTROL PARAMETERS \\
\hline$B_{1}=10, B_{2}=20000, B_{3}=7, B_{4}=500$ \\
PARAMETERS OF THE EMULATED WIND TURBINE \\
\hline$R=1.5 \mathrm{~m}, J_{t}=0.1 \mathrm{~kg} \cdot \mathrm{m}^{2}, C_{p \max }=0.4760, \lambda=7$ \\
PARAMETERS OF THE DC MOTOR \\
\hline $6.5 \mathrm{~kW}, 3850 \mathrm{rpm}, 310 \mathrm{~V}, 24.8 \mathrm{~A}$ \\
\hline$R_{s}=78, R_{r}=0.78 \Omega, L_{r}=3.6 \mathrm{H}, J=0.02 \mathrm{~kg} \cdot \mathrm{m}^{2}$ \\
PARAMETERS OF THE TESTED DFIG \\
\hline$R_{s}=0.325 \Omega, L_{s}=4.75 \mathrm{mH}, R_{r}=0.13 \Omega, L_{r}=1.03 \mathrm{mH}$, \\
$M=57.3 \mathrm{mH}, p=2$
\end{tabular}

\section{ACKNOWLEDGMENT}

The authors would like to thank Prof. S. Bacha from the Grenoble Electrical Engineering Laboratory, Grenoble, France, for allowing the use of the renewable energy experimental facilities.

\section{REFERENCES}

[1] M. Liserre, R. Cardenas, M. Molinas, and J. Rodriguez, "Overview of multi-MW wind turbines and wind parks," IEEE Trans. Ind. Electron., vol. 58, no. 4, pp. 1081-1095, Apr. 2011.

[2] F. D. Bianchi, H. de Battista, and R. J. Mantz, Wind Turbine Control Systems. Principles, Modelling and Gain Scheduling Design. London, U.K.: Springer, 2007.

[3] B. Beltran, M. E. H. Benbouzid, and T. Ahmed-Ali, "High-order sliding mode control of a DFIG-based wind turbine for power maximization and grid fault tolerance," in Proc. IEEE Int. Elect. Mach. Drives Conf., Miami, FL, May 2009, pp. 183-189.

[4] B. Beltran, T. Ahmed-Ali, and M. E. H. Benbouzid, "Sliding mode power control of variable speed wind energy conversion systems," IEEE Trans. Energy Convers., vol. 23, no. 22, pp. 551-558, Jun. 2008.

[5] M. Tazil, V. Kumar, R. C. Bansal, S. Kong, Z. Y. Dong, W. Freitas, and H. D. Mathur, "Three-phase doubly fed induction generators: An overview," IET Elect. Power Appl., vol. 4, no. 2, pp. 75-89, Feb. 2010.

[6] C. H. Liu and Y. Y. Hsu, "Effect of rotor excitation voltage on steady-state stability and maximum output power of a doubly fed induction generator," IEEE Trans. Ind. Electron., vol. 58, no. 4, pp. 1096-1109, Apr. 2011.

[7] T. Senjyu, R. Sakamoto, N. Urasaki, T. Funabashi, H. Fujita, and H. Sekine, "Output power leveling of wind turbine generator for all operating regions by pitch angle control," IEEE Trans. Energy Convers., vol. 21, no. 2, pp. 467-475, Jun. 2006. 
[8] R. Pena, R. Cardenas, J. Proboste, G. Asher, and J. Clare, "Sensorless control of doubly-fed induction generators using a rotor-current-based MRAS observer," IEEE Trans. Ind. Electron., vol. 55, no. 1, pp. 330339, Jan. 2008.

[9] L. Xu and P. Cartwright, "Direct active and reactive power control of DFIG for wind energy generation," IEEE Trans. Energy Convers., vol. 21, no. 3, pp. 750-758, Sep. 2006.

[10] R. Cardenas, R. Pena, J. Proboste, G. Asher, and J. Clare, "MRAS observer for sensorless control of standalone doubly fed induction generators," IEEE Trans. Energy Convers., vol. 20, no. 4, pp. 710-718, Dec. 2005.

[11] R. Vepa, "Nonlinear, optimal control of a wind turbine generator," IEEE Trans. Energy Convers., vol. 26, no. 2, pp. 468-478, Jun. 2011.

[12] I. MunteanuS. Bacha, A. I. Bratcu, J. Guiraud, and D. Roye, "Energyreliability optimization of wind energy conversion systems by sliding mode control," IEEE Trans. Energy Convers., vol. 23, no. 3, pp. 975985, Sep. 2008.

[13] F. Valenciaga and P. F. Puleston, "Variable structure control of a wind energy conversion system based on a brushless doubly fed reluctance generator," IEEE Trans. Energy Convers., vol. 22, no. 2, pp. 499-506, Jun. 2008

[14] S. Benelghali, M. E. H. Benbouzid, J. F. Charpentier, T. Ahmed-Ali, and I. Munteanu, "Experimental validation of a marine current turbine simulator: Application to a PMSG-based system second-order sliding mode control," IEEE Trans. Ind. Electron., vol. 58, no. 1, pp. 118-126, Jan. 2011.

[15] B. Beltran, T. Ahmed-Ali, and M. E. H. Benbouzid, "High-order sliding mode control of variable speed wind turbines," IEEE Trans. Ind.Electron., vol. 56, no. 9, pp. 3314-3321, Sep. 2009.

[16] F. Valenciaga and P. F. Puleston, "High-order sliding control for a wind energy conversion system based on a permanent magnet synchronous generator," IEEE Trans. Energy Convers., vol. 23, no. 3, pp. 860-867, Sep. 2008.

[17] A. Levant and L. Alelishvili, "Integral high-order sliding modes," IEEE Trans. Autom. Control, vol. 52, no. 7, pp. 1278-1282, Jul. 2007.

[18] (2011). [Online]. Available: http://wind.nrel.gov/designcodes/simulators/fast/.

[19] R. Fadaeinedjad, M. Moallem, and G. Moschopoulos, "Simulation of a wind turbine with doubly fed induction generator by FAST and Simulink," IEEE Trans. Energy Convers., vol. 23, no. 2, pp. 690-700, Jun. 2008.

[20] A. Manjock "Design codes FAST and ADAMS ${ }^{\circledR}$ for load calculations of onshore wind turbines," Germanischer Lloyd WindEnergie GmbH, Hamburg, Germany, Rep. 72042, May 26, 2005.

[21] F. Poitiers, T. Bouaouiche, and M. Machmoum, "Advanced control of a doubly-fed induction generator for wind energy conversion," Elect. Power Syst. Res., vol. 79, no. 7, pp. 1085-1096, Jul. 2009.

[22] R. Cardenas and R. Pena, "Sensorless vector control of induction machines for variable-speed wind energy applications," IEEE Trans. Energy Convers., vol. 19, no. 1, pp. 196-205, Mar. 2004.

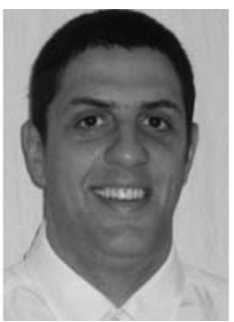

Brice Beltran was born in Arles, France, in 1981. He received the Engineer Degree in electrical engineering from the Ecole Nationale Supérieure d'Ingénieurs des Etudes et Techniques d'Armement, Brest, France, and the Ph.D. degree in electrical engineering from the University of Brest, Brest, in 2006 and 2010, respectively.

In 2006, he joined the Délégation Générale pour l'Armenent as an Engineer and Technical Expert in information systems. In January 2010, he joined the Brest Laboratory of Mechanics and Systems, University of Brest, as an Associate Member. His current research interests include modeling and control of renewable energy applications.

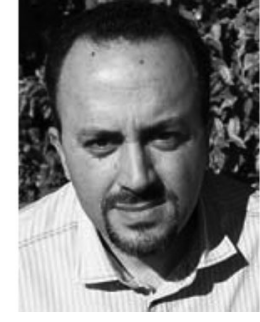

Mohamed EI Hachemi Benbouzid (S'92-M'95SM'98) was born in Batna, Algeria, in 1968. He received the B.Sc. degree in electrical engineering from the University of Batna, Batna, in 1990, the M.Sc. and $\mathrm{Ph} . \mathrm{D}$. degrees in electrical and computer engineering from the National Polytechnic Institute of Grenoble, Grenoble, France, in 1991 and 1994, respectively, and the Habilitation à Diriger des Recherches degree from the University of Picardie "Jules Verne," Amiens, France, in 2000

After receiving the Ph.D. degree, he joined the Professional Institute of Amiens, University of Picardie "Jules Verne," where he was an Associate Professor of electrical and computer engineering. Since September 2004, he has been with the Institut Universitaire de Technologie of Brest, University of Brest, Brest, France, where he is a Professor of electrical engineering. His main research interests and experience include analysis, design, and control of electric machines, variable-speed drives for traction, propulsion, and renewable energy applications, and fault diagnosis of electric machines.

Dr. Benbouzid is a senior member of the IEEE Power Engineering, Industrial Electronics, Industry Applications, Power Electronics, and Vehicular Technology Societies. He is an Associate Editor of the IEEE TRANSACTIONS ON ENERGY CONVERSION, the IEEE TRANSACTIONS ON INDUSTRIAL ELECTRONICS, the IEEE TRANSACTIONS ON VeHICULAR TECHNOLOGY, and the IEEE/ASME TRANSACTIONS ON MECHATRONICS.

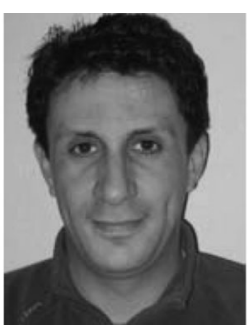

Tarek Ahmed-Ali was born in Algiers, Algeria, in 1972. He received the B.Sc. degree in electrical engineering from the Ecole Nationale Polytechnique of Algiers, Algiers, in 1994, the M.Sc. degree in electrical and computer engineering from the University of Paris VI, Paris, France, in 1995, and the Ph.D. degree in electrical and computer engineering from the University of Paris Sud, Paris, in 1998.

In 1998, he joined the University of Paris XIII, Paris, as a Teaching and Research Assistant. In 1998, he was also with the Ecole Centrale de Lille, Lille, France, as a Teaching and Research Assistant. In 2000, he joined Société Nationale des Chemins de fer français (the French National Railway Corporation) as a Research and Development Engineer. In 2002, he became a Lecturer in control engineering at Ecole Nationale des Ingénieurs des Etudes et Techniques de l'Armement, Brest, France. In 2008, he joined as an Associate Professor at the University of Caen, Caen, France, where he became a Professor of automatic control in 2010. His main research interests include sliding mode control, nonlinear observers, and fault-tolerant control and diagnosis in the field of ac drives. 